\title{
Collaboration scripts and scaffolding
}

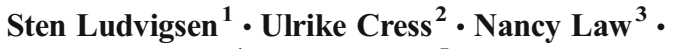 \\ Carolyn P. Rosé ${ }^{4} \cdot$ Gerry Stahl $^{5}$
}

Published online: 15 November 2016

(C) International Society of the Learning Sciences, Inc. 2016

This issue contains papers from two different genres of CSCL research. First, we have chosen to present two papers that address important issues related to group formation, cognitive group awareness, and the automatization of approaches for improving students' learning processes and outcomes. These studies show clearly how learning can become more productive with computational support. The two other studies are part of the tradition that describes, categorizes, and analyzes important interactional details supported in or by computational tools. All four studies offer new insights into the genesis of specific design features for productive student learning. In some of the papers, the role of teachers is discussed. The teacher's role is important in CSCL studies as an interactional partner scaffolding students in their efforts to become more productive in their academic work.

\section{Classroom discourse and automatic feedback}

The focus of the paper by Melanie Erkens, Daniel Bodemer, and Ulrich Hoppe is on how to scaffold teachers and students through automatic analysis and feedback. This paper grows out of the school of thought that the CSCL environment can enhance and regulate teaching and learning activities through orchestration and scaffolding (Dillenbourg and Jermann 2007; Fischer et al. 2013; Stegmann et al. 2016; Tchounikine 2016). In this paper, the authors analyze teachers' work, investigating how teachers need to appropriate new computational tools into their classroom routine. Classrooms are of course not fixed environments; the

Sten Ludvigsen exec@ijcscl.org

1 University of Oslo, Oslo, Norway

2 Knowledge Media Research Center, Tübingen, Germany

3 University of Hong Kong, Hong Kong, China

4 Carnegie Mellon University, Pittsburgh, PA, USA

5 Drexel University, Philadelpia, PA, USA 
complexity of classroom activities needs to be recognized, and teachers must recognize the advantages of using new computational tools and ultimately embedding them in their daily routines.

Erkens et al. argue that a combination of heterogeneous-group formation and cognitive group-awareness tools might provide an effective way to support and regulate students' learning (Järvelä et al. 2016). They develop a text-mining tool that can support both teachers and students in the classroom. This tool makes it possible to transform students' written text into variables, and to use the variables for forming groups and visualizing information from a cognitive perspective. The tool they use in the experiment is called a group and representation tool (GRT). The results from this study are positive for both students and teachers. The GRT is able to scaffold the students' learning processes and lead to improved outcomes under specific conditions. This study is meant to spark discussion regarding how the CSCL field can take steps forward in using automatic feedback. Data from automatic feedback, in combination with other forms of analysis, can enrich our understanding of teachers' work while it also improves students' learning.

\section{Agent technology to enhance productive dialogues}

In the paper by Stergios Tegos, Stavros Demetriadis, Pantelis Papadopoulos, and Armin Weinberger, the focus is on conversational agents that prompt students to advance their peer dialogue. It is a nontrivial task to enhance students' communication to an academically productive level, and there have been many approaches within CSCL to address this problem. Descriptive studies have tried to identify moves and patterns that can lead to productive talk, and have developed scripts for collaborative efforts (Furberg 2016; Stegmann et al. 2016; Tchounikine 2016). Recent advances in computational linguistics make it possible to tailor prompts for the students. The students involved in this study were in their second year of a computer science program, and the research is conducted within their human-computer interaction course.

The model used in the study is built on three main elements - the peer interactions, the domain, and the intervention approach. The study is of an experimental nature, with pre- and post-test treatment and control groups. The results show that the prompt by the conversational agents lead to improved outcomes for the students, not only at the individual level but also at the level of the dyad as a whole. The prompt asks the students to become more explicit in their reasoning, which also implies that the sources that the students use become transparent for other students in the community. Another interesting finding is the students' perception of the disruptive aspect of the agent's interventions, and that the students experience and react to the automatic disruptions differently. This study represents an important step forward for the field of agent technologies as a support for advancing student talk. Teachers can of course increase the quality of talk through more subtle, varied, and contextualized forms of intervention, but the teacher is a limited resource, and tools that can help students to increase their explicitness and reasoning in conversation with others are potentially helpful.

Both studies presented so far build on recent work in the area of automated collaborative process analysis (Rosé et al. 2008; Mu et al. 2012; Gweon et al. 2013) and dynamic support for collaborative learning (Wang et al. 2011; Adamson et al. 2014), which have been of interest in this journal for some time (e.g., Berland et al. 2015; Dascalu et al. 2015; 
Erkens and Janssen 2008). This line for research gives news perspectives on what computational tools can do to support learning.

\section{Discourse patterns in asynchronous online discussion}

In the paper by Ella Lai Fan Fu, Jan. van Aalst, and Carol K. K. Chan, the focus is on the classification of discourse patterns in asynchronous online discussions. The authors' stance is based on knowledge-building design principles (for recent contributions see Chen et al. 2015; Resendes et al. 2015). Knowledge building is one of the fields within CSCL where we have a solid accumulation of knowledge, as many facets of knowledge building have been studied by scholars in different regions worldwide. In this contribution, Fu et al. use a coding scheme with dimensions such as agency, community, idea, information, linking, meta-discourse, and questions, as they make use of different methods, such as thematic analysis, qualitative coding, and narrative analysis.

The authors identify seven discourse patterns within three modes of discourse. These discourse patterns can be divided into three clusters. The first is knowledge sharing, where we can distinguish fact-oriented, cumulative, repetitive, and simple argumentation as disputational talk. This cluster shows that not all patterns are equally productive for learning. The second cluster, knowledge construction, is divided into two types of discourse: explanatory and problem-centered inquiry, as well as complex argumentation. In these forms of discourse, students can advance their understanding and forms of participation. A third discourse pattern, knowledge building, also contains two forms of discourse. One is progressive inquiry and the other is sustained discourse and community advancement. In such discourse, the participants advance their understanding through the collective advancement of the community.

An implication of this study is that teachers, when aware of different discourse patterns, can work systematically to scaffold students to work towards an epistemic orientation and stance. Teachers can use such insights when planning their work in and across subjects in school settings.

\section{Unit of analysis, microanalysis in science settings}

The contribution by Hans C. Arnseth and Ingeborg Krange uses ethnographic description in combination with detailed interaction analysis of how students work on inquiry problems in science. Their study investigates how students in upper-secondary school try to understand phenomena of energy and energy transformation. The paper is part of an important approach in CSCL. Based on either a socio-cultural or situated stance towards collaboration, one tries to describe and analyze how interaction and learning takes place turn by turn over time in terms of learning trajectories (Stahl et al. 2014; Stahl 2015; Furberg 2016; Enyedy et al. 2015). This study follows a new line of research that involves teachers as part of the activities. In naturalistic educational settings, the teacher plays an important role, and we must know more about how teachers can enhance specific social and cognitive functions.

Arnseth and Krange argue that the unit of analysis needs to be a functional system incorporating tools. The line of reasoning adopted in this paper builds on the work of Vygotsky and Wertsch. Such a stance opens up for understanding the multiple parts of the 
functional systems, or in other words the multiplicity of activities. Multiplicity means that the collaboration between students and computational tools can take multiple paths. As analysts, we need to understand how the participants orient themselves through a series of activities and why they choose specific paths. The ways Arnseth and Krange analyze their data on multiple levels and offer ethnographic descriptions and detailed micro-analysis provide new accounts of how we can understand CSCL settings in institutions like schools.

\section{Squibs}

We remind all CSCL researchers to contribute to the new Squibs format.

While the mainstay of $i j C S C L$ has been full-length journal papers with substantial elaborations of theoretical frameworks, we are introducing a new genre of submission that we hope will be effective in sparking reflection, discussion, and growth in the field. We call this new genre of submission Squibs, in the tradition of the Computational Linguistics Journal where this genre was first created. This type of submission may include short articles reporting technical advancements, brief discussions of thought-provoking findings, cutting-edge algorithms, or new data or tools of interest to the journal readership. These articles may also be focused on raising awareness of an emerging trend, a proposed change in practices within the field, or debates on theoretical and/or methodological issues. The contributions of these articles are meant to be positioned on the edges of the field, challenging our boundaries and our thinking. The shorter format is intended to facilitate a quicker turnaround time, and thus provide a means for timely discussions in the field. Squib submissions should generally not exceed 3000 words. We have already received some submissions in this new category, and we look forward to including publications in this genre in up-coming issues.

\section{References}

Adamson, D., Dyke, G., Jang, H. J., \& Rosé, C. P. (2014). Towards an agile approach to adapting dynamic collaboration support to student needs. International Journal of AI in Education, 24(1), 91-121.

Berland, M., Davis, D., \& Smith, C. P. (2015). Amoeba: Designing for collaboration in computer science classrooms through live learning analytics. International Journal of Computer-Supported Collaborative Learning, 10(4), 425-447.

Chen, B., Scardamalia, M., \& Bereiter, C. (2015). Advancing knowledge-building discourse through judgments of promising ideas. International Journal of Computer-Supported Collaborative Learning, 10(4), 345-366.

Dascalu, M., Trausan-Matu, S., McNamara, D. S., \& Dessus, P. (2015). Readerbench: Automated evaluation of collaboration based on cohesion and dialogism. International Journal of Computer-Supported Collaborative Learning, 10(4), 395-423.

Dillenbourg, P., \& Jermann, P. (2007). Designing integrative scripts. In F. Fischer, I. Kollar, H. Mandl, \& J. M. Haake (Eds.), Scripting computer-supported collaborative learning: Cognitive, computational, and educational perspectives (pp. 275-301). New York: Springer.

Enyedy, N., Danish, J. A., \& DeLiema, D. (2015). Constructing liminal blends in a collaborative augmented-reality learning environment. International Journal of Computer-Supported Collaborative Learning, 10, 7-34.

Erkens, G., \& Janssen, J. (2008). Automatic coding of dialogue acts in collaboration protocols. International Journal of Computer-Supported Collaborative Learning, 3(4), 447-470.

Fischer, F., Kollar, I., Stegmann, K., \& Wecker, C. (2013). Toward a script theory of guidance in computersupported collaborative learning. Educational Psychologist, 48(1), 56-66.

Furberg, A. (2016). Teacher support in computer-supported lab work: Bridging the gap between lab experiments and students' conceptual understanding. International Journal of Computer-Supported Collaborative Learning, 11, 89-113. 
Gweon, G., Jain, M., Mc Donough, J., Raj, B., \& Rosé, C. P. (2013). Measuring prevalence of other-oriented Transactive contributions using an automated measure of speech style accommodation. International Journal of Computer-Supported Collaborative Learning, 8(2), 245-265.

Järvelä, S., Kirschner, P. A., Hadwin, A., et al. (2016). Socially shared regulation of learning in CSCL: Understanding and prompting individual- and group-level shared regulatory activities. International Journal of Computer-Supported Collaborative Learning, 11, 263-280.

Mu, J., Stegmann, K., Mayfield, E., Rosé, C. P., \& Fischer, F. (2012). The ACODEA framework: Developing segmentation and classification schemes for fully automatic analysis of online discussions. International Journal of Computer-Supported Collaborative Learning, 7(2), 285-305.

Resendes, M., Scardamalia, M., Bereiter, C., Chen, B., \& Halewood, C. (2015). Group-level formative feedback and metadiscourse. International Journal of Computer-Supported Collaborative Learning, 10, 309-336.

Rosé, C. P., Wang, Y. C., Cui, Y., Arguello, J., Stegmann, K., Weinberger, A., \& Fischer, F. (2008). Analyzing collaborative learning processes automatically: Exploiting the advances of computational linguistics in computer-supported collaborative learning. International Journal of Computer-Supported Collaborative Learning, 3(3), 237-271.

Stahl, G. (2015). A decade of CSCL. International Journal of Computer-Supported Collaborative Learning, 10 , 337-344.

Stahl, G., Cress, U., Ludvigsen, S., \& Law, N. (2014). Dialogic foundations of CSCL. International Journal of Computer-Supported Collaborative Learning, 9, 117-125.

Stegmann, K., Kollar, I., Weinberger, A., et al. (2016). Appropriation from a script theory of guidance perspective: A response to Pierre Tchounikine. International Journal of Computer-Supported Collaborative Learning, 11, 371-379.

Tchounikine, P. (2016). Contribution to a theory of CSCL scripts: Taking into account the appropriation of scripts by learners. International Journal of Computer-Supported Collaborative Learning, 11, 349-369.

Wang, H. C., Rosé, C. P., \& Chang, C. Y. (2011). Agent-based dynamic support for learning from collaborative brainstorming in scientific inquiry. International Journal of Computer-Supported Collaborative Learning, 6(3), 371-396. 